\title{
Photo-induced iodination of aryl halides under very mild conditions
}

\author{
Lu Li ${ }^{1-3}$, Wenbo Liu ${ }^{1,3}$, Xiaoyue $\mathrm{Mu}^{1}$, Zetian $\mathrm{Mi}^{2}$ \& Chao-Jun Li ${ }^{1}$
}

\begin{abstract}
${ }^{1}$ Department of Chemistry and FQRNT Centre for Green Chemistry and Catalysis, McGill University, Montreal, Quebec, Canada. ${ }^{2}$ Department of Electrical and Computer Engineering, McGill University, Montreal, Quebec, Canada. ${ }^{3}$ These authors contributed equally to this work. Correspondence should be addressed to C.-J.L. (cj.li@mcgill.ca) or Z.M. (zetian.mi@mcgill.ca).
\end{abstract}

Published online 15 September 2016; doi:10.1038/nprot.2016.125

\begin{abstract}
Aryl iodides are important precursors in synthetic chemistry that form carbon-carbon and carbon-heteroatom bonds. Most methods use transition-metal catalysts, which need to be scrupulously removed before the compounds can be used in the pharmaceutical and electronics industries, where only parts-per-million levels of transition metals are allowed. The aromatic Finkelstein iodination reaction is a powerful method of preparing valuable aryl iodides from cheap but less reactive aryl bromides and chlorides. This protocol describes a transition metal-free method for a photo-induced aromatic Finkelstein iodination reaction that is performed at room temperature $\left(20^{\circ} \mathrm{C}\right)$. With common aromatic bromides and sodium iodide $(\mathrm{NaI})$ as the starting materials, as well as a catalytic amount of $I_{2}$ as an additive, the corresponding aromatic iodides can be synthesized in yields ranging from 56 to $93 \%$ under UV light irradiation in the absence of any metal catalysts. Various functional groups such as nitrile, ester and amino can be tolerated, which will facilitate the further functionalization of the aromatic iodides. The procedure normally requires $38-40 \mathrm{~h}$ to complete.
\end{abstract}

\section{INTRODUCTION}

Aromatic (heteroaromatic) halides are valuable and fundamental building blocks that are used to construct new carbon-carbon and carbon-heteroatom bonds in organic synthesis and drug design ${ }^{1-3}$. Many important classical cross-coupling reactions such as the Heck reaction, the Suzuki reaction and the Buchwald-Hartwig reaction, among others, use aryl halides as starting materials (Fig. 1a). These reactions work best when aromatic iodides are used as the starting materials; aromatic chlorides and bromides are less reactive, and they usually require specially designed ligands and harsher conditions (Fig. 1b). Moreover, aryl iodides are useful in their own right and have already found wide application in the medical research field, for example, in hypothyroidism treatment, single-photon-emission computed tomography and preclinical $\mathrm{X}$-ray imaging ${ }^{4-7}$. The existence of different radioactive iodine isotopes ( ${ }^{131} \mathrm{I},{ }^{125} \mathrm{I},{ }^{123} \mathrm{I}$ ) also makes it possible to label the same target agent with different isotopes, which provides additional flexibility in pharmacokinetic studies.

Unfortunately, the synthesis of aryl iodides is not straightforward, because they are usually more reactive than their precursors $^{8}$. The traditional synthesis routes result in poor yields or require stoichiometric amounts of transition-metal reagents ${ }^{9-11}$. A few recently developed copper- or nickel-catalyzed strategies for aryl iodide preparation have been established in which aryl chlorides and bromides react with inorganic iodides such as $\mathrm{NaI}$ or KI (Fig. 2a) ${ }^{12-15}$. However, each of these methods has limited substrate scope and has other limitations, which include a requirement for high temperatures $\left(>100^{\circ} \mathrm{C}\right)$, transition metals $(\mathrm{Cu}$ or $\mathrm{Ni})$ and/or specially designed ligands such as diamine and phosphine ligands. Although transition metals have been widely used in chemical industry as catalysts, they are toxic and must be removed to safe levels for products that are used in the pharmaceutical and electronics industries. These purification steps increase the overall cost of the synthetic process. Ideal synthetic approaches are therefore those that do not require transition metals, take place under milder conditions (e.g., room temperature) and have broad substrate scope. To meet these objectives, we recently developed an efficient and mild protocol to directly synthesize aryl iodides from cheap and abundant aryl chlorides and bromides in combination with NaIs (aromatic Finkelstein iodination) at room temperature (Fig. 2b) ${ }^{16}$. Furthermore, this photochemical strategy is very simple and atom-economical, and does not require any photoredox catalysts or photosensitizers.

Our recent report about the photo-induced aromatic Finkelstein reaction is mechanistically based on the photo-induced single electron transfer from NaI to aryl bromides or aryl chlorides ${ }^{17}$. In

a

Various coupling reactions involving aryl halides

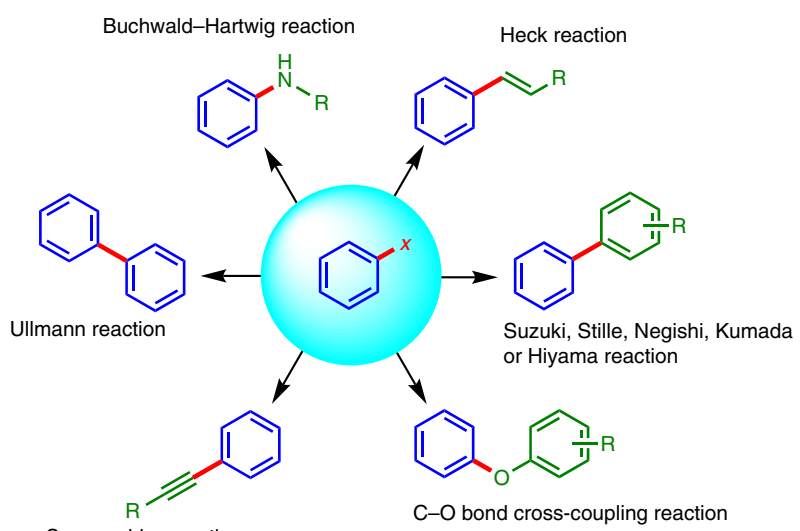

Sonogashira reaction

b Differences in reactivity between $\mathrm{ArCl}, \mathrm{ArBr}$ and $\mathrm{Arl}$ in coupling reactions

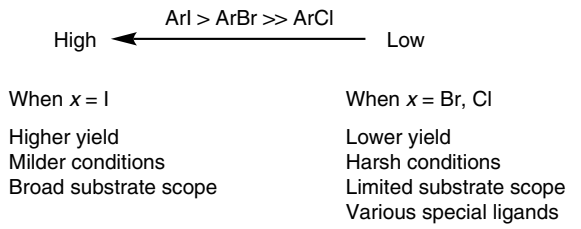

Figure 1 | Applications of aryl halides in organic synthesis. (a) Representative classic coupling reactions involving aryl halides as the starting materials. (b) Reactivity comparison of different aryl halides in coupling reactions. 
a Previous methods<smiles>Brc1ccccc1</smiles>

$\mathrm{Nal}$

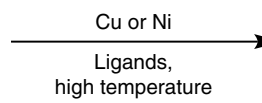<smiles>Ic1ccccc1</smiles>

b



Figure 2 | Current approaches to aromatic halogen exchange. (a) Previous methods of preparing aryl iodides from aryl bromides. (b) Our photochemical method for synthesizing aryl iodides using UV light (254 nm).

this hypothesized mechanism, irradiation of the reagents with UV light results in the transfer of one electron from NaI to aryl bromide, producing an aromatic radical anion species, which undergoes further fragmentation to form an aryl radical and bromide anion. Most aryl radicals can be trapped by an iodine radical, producing the desired product (Fig. 3a, path A), whereas a small portion of aryl radicals will abstract hydrogen from the solvent to form the reducing product. Nevertheless, by adding $2.54 \mathrm{mg}$ of $\mathrm{I}_{2}$, the reducing product can be substantially inhibited, as $\mathrm{I}_{2}$ will compete with the solvent to trap the aryl radical (Fig. 3a, path B). It is noted that in the case of some aryl bromides with strong electron-donating groups, an alternative homolytic $\mathrm{C}-\mathrm{Br}$ bond cleavage mechanism may also operate in competition with the heterolytic route (Fig. $3 \mathbf{b})^{18}$.

Our protocol for the synthesis of aryl iodide is performed at room temperature and is compatible with various functional groups (Fig. 4); all the starting materials are commercially available or easily prepared. Under the optimized conditions, common functional groups such as - $\mathrm{CN}(\mathbf{2 b}, 2 \mathbf{c}, 2 \mathbf{k}),-\mathrm{OCH}_{3}(\mathbf{2 d}, 2 \mathbf{e}, 2 \mathbf{q})$, $-\mathrm{OH}(\mathbf{2 g}, \mathbf{2} \mathbf{l}),-\mathrm{CF}_{3}(\mathbf{2} \mathbf{h}),-\mathrm{NR}_{2}(\mathbf{2} \mathbf{i}),-\mathrm{NH}_{2}(\mathbf{2} \mathbf{x})$, ester $(\mathbf{2} \mathbf{j})$ and ketone $(2 \mathbf{u})$ can be tolerated. Besides the aromatic bromides and chlorides, hetero aryl bromides and chlorides can also be converted into the corresponding hetero aryl iodides smoothly, including pyrimidine (2n), indole (2o), isoquinoline (2v) and quinoline $(2 \mathrm{w})$. In addition, the iodination of $(E)$-1-bromo-2-phenylethene gave a (Z)-1-iodo-2-phenylethene (2y) predominantly. This broad substrate scope will facilitate the further functionalization of the prepared (hetero) aryl iodides, which are extremely useful and important, especially in complex natural product synthesis, among other applications. Moreover, this procedure can be adapted to the gram-scale reaction, which formed the product at an excellent yield $(86 \%, 2 d)$.

In this protocol, we describe a detailed procedure for photoinduced aromatic Finkelstein iodination to prepare aryl iodides from aryl bromides. As an example, we use 4-bromobenzonitrile (1b; Fig. 4) to demonstrate this synthetic approach, as -CN represents a common and highly versatile functional group in organic synthesis. On the basis of our experience, the following protocol would also be applicable to most of the other functional groups mentioned in Figure 4 without further modification. a Heterolytic $\mathrm{C}-\mathrm{Br}$ bond cleavage (photo- $\mathrm{S}_{\mathrm{N}} 1$ mechanism)

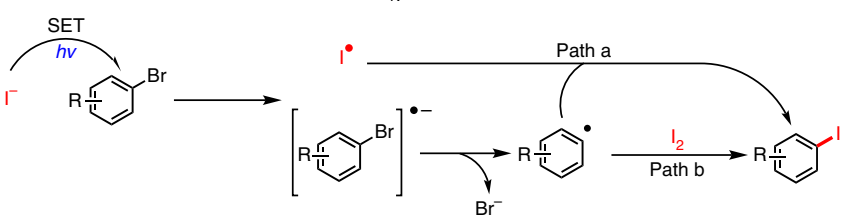

b Homolytic C-Br bond cleavage

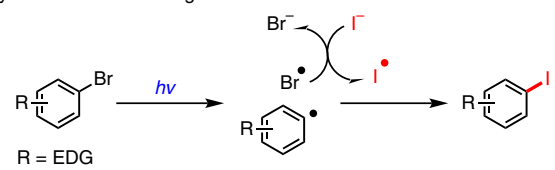

Figure 3 | Hypothesis for the mechanism of this photo-induced aromatic Finkelstein reaction. (a) Heterolytic approach. (b) Homolytic approach. EDG, electron-donating group.

\section{Experimental design}

Reaction vessels and UV lamps. All the small-scale $(0.1 \mathrm{mmol})$ reactions are conducted in 10-ml quartz tubes with screw caps and septums, which were purchased from Technical Glass Products,

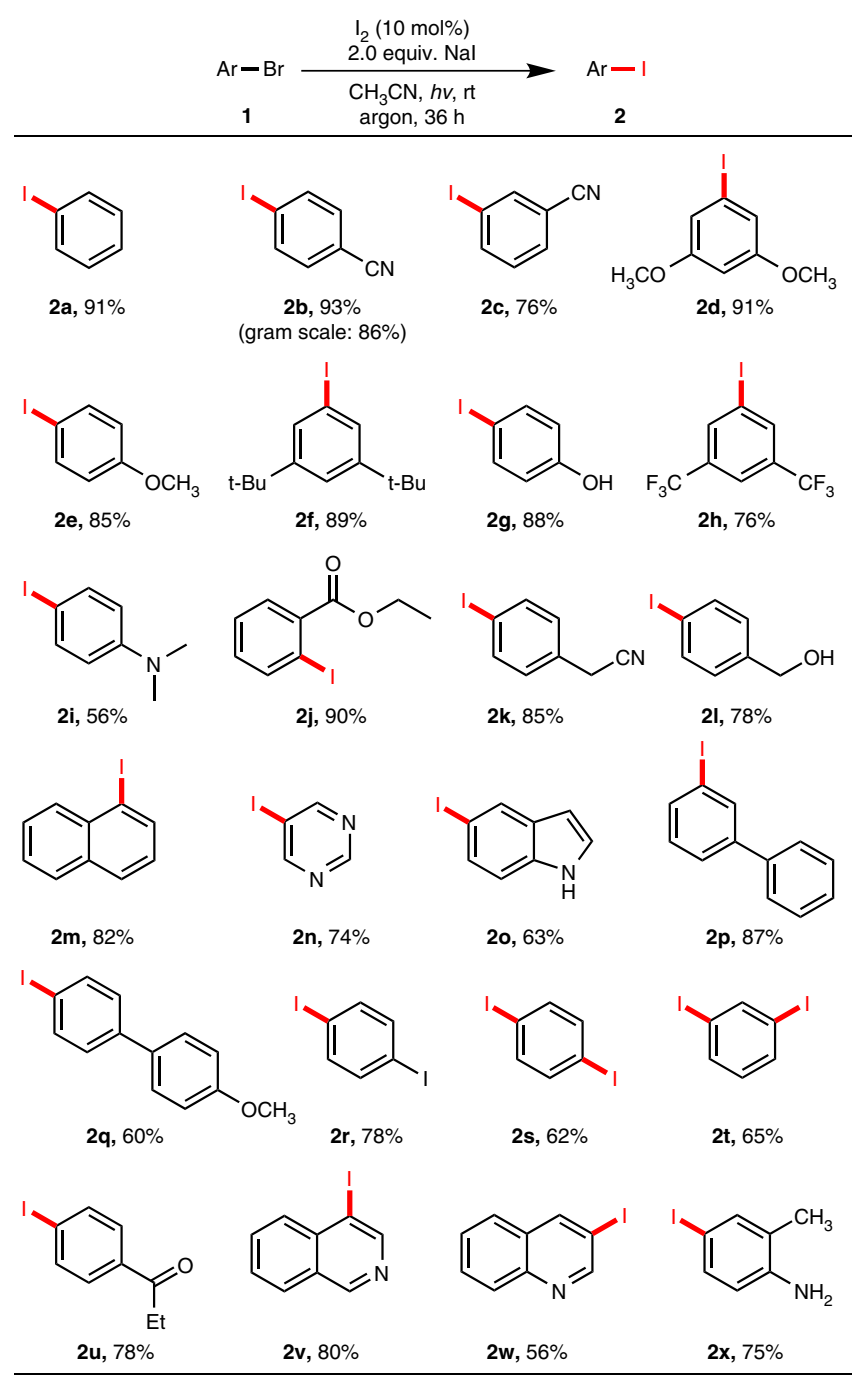

Figure 4 | Examples of aryl iodides that we have prepared at room temperature (rt) with UV light $(254 \mathrm{~nm})$ using this protocol. Percentage yields were determined by GC-MS. 
located in Painesville Township, Ohio; the UV LZC-4V photoreactor was purchased from Luzchem, located in Ottawa, Canada.

Scale of the reaction. Generally, the protocol described here represents both $0.1 \mathrm{mmol}-$ scale (Steps 1-9) and $6.0 \mathrm{mmol}-\mathrm{scale}$ (Steps 10-20) reactions, in which aryl bromide or chloride is the limiting reagent. Our experience with this reaction shows that the smaller reaction scale results in a higher yield. Therefore, if the reader desires to run a larger-scale reaction, in order to guarantee a reasonable yield, the use of a larger reaction vessel and a stronger lamp is highly recommended.

Solvent amount. As shown in Figure 4, most of the desired iodobenzene was obtained in an optimal yield by using $0.5 \mathrm{ml}$ of acetonitrile (bromobenzene $0.2 \mathrm{M}$ ), and several of the substrates $(\mathbf{2} \mathbf{p}, \mathbf{2 u}-\mathbf{2} \mathbf{x})$ required a more dilute solution (bromobenzene $0.067 \mathrm{M}$ ) for optimal yields obtained by using $1.5 \mathrm{ml}$ of acetonitrile for optimal yields.

\section{MATERIALS}

REAGENTS

I CAUTION Personal protective equipment, including UV protection goggles, lab coat and gloves, must be worn during the manipulation because all the reagents are potentially dangerous and UV light is harmful to the eyes. All the reagents are used directly without further purification, unless otherwise specified.

- 4-Bromobenzonitrile ( $p$-BrArCN, $\geq 99 \%$; Sigma-Aldrich, cat. no. B58407)

- Sodium iodide (NaI, $\geq 99.5 \%$; Sigma-Aldrich, cat. no. 383112)

- Iodine $\left(\mathrm{I}_{2}, \geq 99.8 \%\right.$; Sigma-Aldrich, cat. no. 207772)

- Acetonitrile $\left(\mathrm{CH}_{3} \mathrm{CN} 99.8 \%\right.$; Sigma-Aldrich, cat. no. 271004)

- Ethyl acetate $\left(\mathrm{CH}_{3} \mathrm{CO}_{2} \mathrm{C}_{2} \mathrm{H}_{5}, 99.8 \%\right.$; Sigma-Aldrich, cat. no. 270989)

- Hexane, mixture of isomers $\left(\mathrm{C}_{6} \mathrm{H}_{14}, 99 \%\right.$; Sigma-Aldrich, cat. no. 227064)

- Sodium sulfate $\left(\mathrm{Na}_{2} \mathrm{SO}_{4}, \geq 99.0 \%\right.$; Sigma-Aldrich, cat. no. 239313)

- Sodium thiosulfate $\left(\mathrm{Na}_{2} \mathrm{~S}_{2} \mathrm{O}_{3}, \geq 98.0 \%\right.$; Sigma-Aldrich, cat. no. 72049)

- Liquid nitrogen (N2, $\geq 99.998 \%$; Praxair Canada, cat. no. E-4630-L)

- Argon (Ar, $\geq 99.999 \%, 5$ N; Praxair Canada, cat. no. E-4563-L)

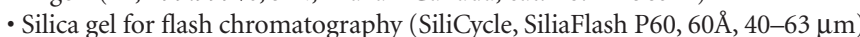

- Deuterated chloroform $\left(\mathrm{CDCl}_{3}\right.$; Cambridge Isotope Laboratories) for NMR EQUIPMENT

- Quartz tube with screw-thread cap and PTFE seal septum (Technical Glass

Products, $10 \mathrm{ml}$, cat. no. SC18)

- PTFE-coated magnetic stir bar (VWR, cross shape, $10 \times 10 \mathrm{~mm}$, cat. no. 4420394)

- Photoreactor with 6 top and 8 side UVC (254-nm) lamps (Luzchem LZC-4V)

- 300 W Xenon lamp with UV light source (Atlas Specialty Lighting)

- Schlenk line (ultra-high purity ( $\geq 99.999 \%$ )-grade argon)

- Vacuum pump (Edwards Vacuum E2M28, cat. no. A37317984)

- Optical power meter (Newport Corporation, cat. no. 1918-R)

-225-nm Long-pass optical filter (Newport Corporation, $50.8 \times 50.8 \mathrm{~mm}$, cat. no. 20CGA-225)

- Round-bottom quartz flask (Quartz Scientific, $50 \mathrm{ml}$, cat. no. 311B001)

- Jacketed quartz container (CANSCI Glass Products, 1 1, custom design and manufacture)

- Disposable syringes and injection needles

- Balance

- Rotary evaporator

\section{PROCEDURE}

$\triangle$ CRITICAL If you want to perform the gram-scale reaction, start at Step 10.

$\triangle$ CRITICAL To rigorously exclude trace amounts of oxygen from the reaction mixture, use a high-vacuum pump $(<2 \mathrm{~Pa})$ and ultrapurified argon gas ( $>99.999 \%$ ).

\section{Small-scale reaction-reaction setup TIMING $20 \mathrm{~min}$}

1) Weigh $18.4 \mathrm{mg}$ of 4-bromobenzonitrile (1b) and $30 \mathrm{mg}$ of $\mathrm{NaI}$ into a $10-\mathrm{ml}$ quartz tube with a cross-shaped stir bar (Fig. 5a). Add $450 \mu \mathrm{l}$ of $\mathrm{CH}_{3} \mathrm{CN}$ to the quartz tube and stir until fully dissolved (Fig. 5 b). Add $50 \mu$ of $\mathrm{I}_{2}$ solution (0.2 $\mathrm{M}$ in $\mathrm{CH}_{3} \mathrm{CN}$ ) dropwise to the quartz tube (Fig. 5c) while stirring, and then cap the quartz tube and further stir the mixture until there is no more color change (Fig. $5 \mathrm{~d}$ ).
- Adjustable-volume pipette (Fisherbrand, 10-100 $\mu$ l, cat. no. 21-377-819)

- Rubber bulb

- Dewar

- Round-bottom flask

- Stir plate

- Spatula

- Weighing paper

- Büchner funnel (VWR, 87 ml, cat. no. 89038-120)

- Separation funnel

- Erlenmeyer flask

- Automated flash purification system (Biotage Isolera Prime, cat. no. ISO-PSV)

- Ultra-Fast Flash Chromatography Cartridges (Biotage SNAP Ultra, $10 \mathrm{~g}$, cat. no. FSUL-0442-0010)

- Test tubes to collect the fractions during the flash column chromatography (Fisher, borosilicate glass, $13 \times 100 \mathrm{~mm}$ )

- NMR spectrometers

- Preparative thin-layer chromatography (TLC) plate (EMD Chemicals, Silica gel 60F254, layer thickness $250 \mu \mathrm{m}$ )

\section{REAGENT SETUP}

Dry and degassed $\mathrm{CH}_{3} \mathrm{CN}$ Purify and dry the $\mathrm{CH}_{3} \mathrm{CN}$ with a commercially available solvent purification system. The collected $\mathrm{CH}_{3} \mathrm{CN}$ should be put into the quartz tube, which should be degassed by using a freeze-pump-thaw procedure (four times). The purified $\mathrm{CH}_{3} \mathrm{CN}$ should then be used immediately. Commercial 4-bromobenzonitrile, $\mathrm{I}_{2}$ and $\mathrm{NaI}$ should be used without any purification. They can be stored at $25^{\circ} \mathrm{C}$ on a shelf in the dark without any precautionary measures, and they remain stable for years.

\section{EQUIPMENT SETUP}

Gas chromatography-mass spectrometry Perform GC-MS analysis on an Agilent $6890 \mathrm{~N}$ gas chromatograph combined with an Agilent 5975 mass selective detector and an Agilent 7693A automatic liquid sampler. The method for monitoring the reaction is as follows: (i) start at $60^{\circ} \mathrm{C}$ and hold this temperature for $5 \mathrm{~min}$; (ii) gradually increase the temperature to $280^{\circ} \mathrm{C}$ at a constant rate of $30^{\circ} \mathrm{C}$ per min; and (iii) hold the temperature at $280^{\circ} \mathrm{C}$ for $8 \mathrm{~min}$ and then cool down. The same method can also be used for other compounds listed in Figure 4.
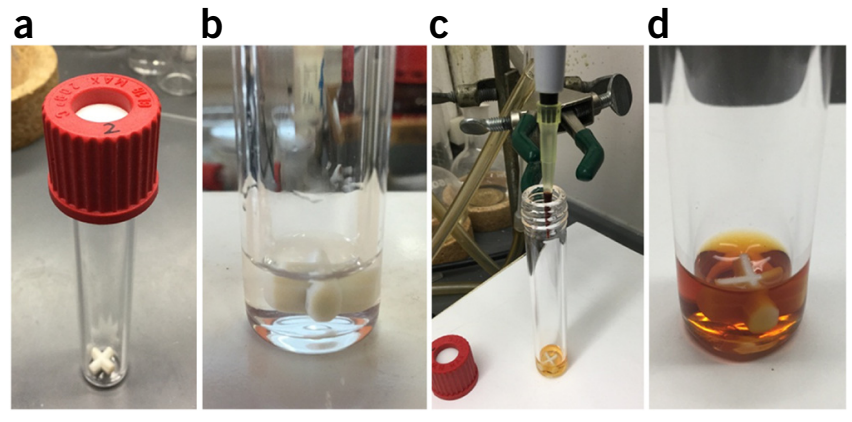

Figure 5 | Reaction setup for Step 1. (a) Airtight quartz tube with the cross-shaped stir bar. (b) The clear solution of $\mathrm{NaI}$ and $\mathrm{ArBr}$ in acetonitrile. (c) Addition of $\mathrm{I}_{2}$ solution. (d) The final homogeneous reactant mixture. 


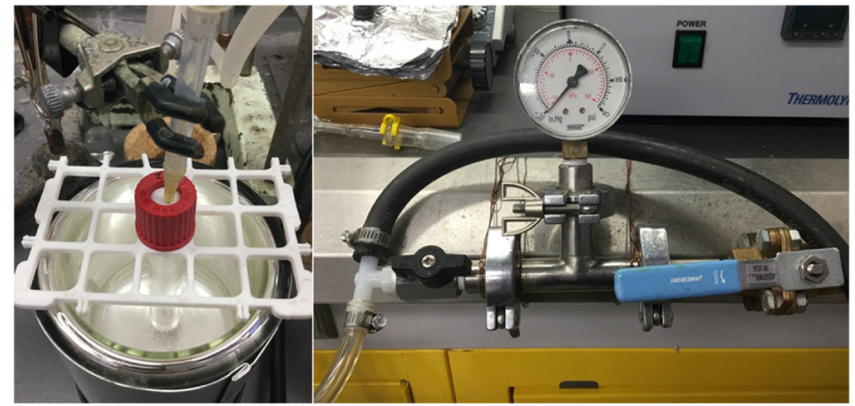

Figure 6 | System degassing by the freeze-pump-thaw operation. Left, freezing and evacuating the mixture in liquid nitrogen. Right, monitoring the system vacuum level with a vacuum gauge.

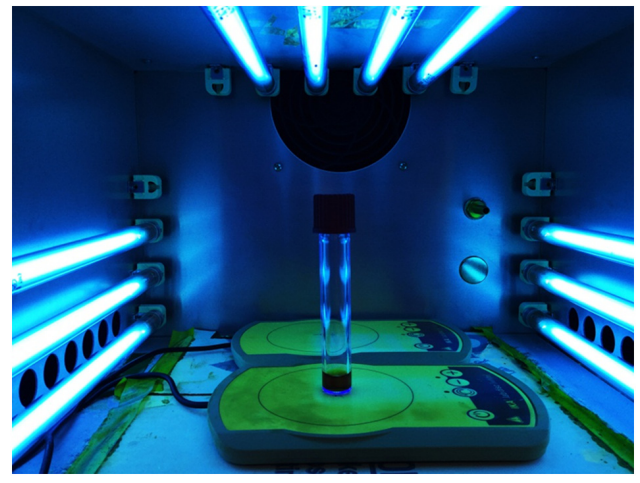

Figure 7 | Photoreaction carried out in the LZC-4V photoreactor.

2| Put the quartz tube into a liquid nitrogen bath to freeze the mixture (Fig. 6). Use the pump to evacuate the quartz tube for $1 \mathrm{~min}$, and then refill it with ultra-purity-grade argon. Thaw the mixture slowly by removing it from liquid nitrogen and placing it in air.

$\triangle$ CRITICAL STEP To prevent reactants from spattering on the wall of the quartz tube, the thawing step should be carried out slowly under ambient room conditions instead of using a water bath or a heater.

? TROUBLESHOOTING

3| Repeat Step 2 another three times.

\section{Small-scale reaction-iodination of 4-bromobenzonitrile (1b) under UV irradiation $\bigcirc$ TIMING $36 \mathrm{~h}$}

4| Put the quartz tube with the reactants in the center of the photoreactor. To obtain the optimum stirring efficiency, the tube containing the stir bar should be on top of the stirring magnet contained by the photoreactor. Start the stirring, set the timer for $36 \mathrm{~h}$ and turn on the UV lamp (Fig. 7).

$\triangle$ CRITICAL STEP The reaction proceeds at wavelengths $<300 \mathrm{~nm}$; the reaction does not proceed at all under visible light irradiation. ? TROUBLESHOOTING

5| Stop the reaction after $36 \mathrm{~h}$ by turning off the lamp.

PAUSE POINT The raw products can be stored on the shelf in the dark at room temperature, and they remain stable for at least $2 \mathrm{~d}$.

\section{Small-scale reaction-purification of the product $\bigcirc$ TIMING $2 \mathbf{h}$}

6| Dilute the resulting suspension with $\mathrm{Na}_{2} \mathrm{~S}_{2} \mathrm{O}_{3}$ aqueous solution $(0.01 \mathrm{M}, 10 \mathrm{ml})$ to reduce excess $\mathrm{I}_{2}$, and then transfer all the reactants in the quartz tube to a $60-\mathrm{ml}$ separation funnel. Wash the quartz tube with excess $\mathrm{CH}_{3} \mathrm{CO}_{2} \mathrm{C}_{2} \mathrm{H}_{5}(3 \times 5 \mathrm{ml})$, which should also be transferred to the separation funnel. Finally, add $10 \mathrm{ml}$ of water and $10 \mathrm{ml}$ of $\mathrm{CH}_{3} \mathrm{CO}_{2} \mathrm{C}_{2} \mathrm{H}_{5}$ to the separation funnel.

7| Collect the top layer, and transfer it to an Erlenmeyer flask. Add $1.0 \mathrm{~g}$ of anhydrous $\mathrm{Na}_{2} \mathrm{SO}_{4}$ to the Erlenmeyer flaks. After 30 min, use a Büchner funnel to remove the $\mathrm{Na}_{2} \mathrm{SO}_{4}$.

8| Transfer the organic solution to a round-bottom flask that is connected to the rotary evaporator, which is used to remove the solvent at $40^{\circ} \mathrm{C}$.

9| Purify the residue by preparative TLC plate using $20 \%$ (vol/vol) $\mathrm{CH}_{3} \mathrm{CO}_{2} \mathrm{C}_{2} \mathrm{H}_{5}$ in hexanes to provide the white solid product $\left(R_{\mathrm{f}}=0.56\right)$. Specifically, deposit the crude products in a thin horizontal line at the bottom of the preparative TLC plate, and run the plate by using $100 \mathrm{ml}$ of $20 \%$ (vol/vol) $\mathrm{CH}_{3} \mathrm{CO}_{2} \mathrm{C}_{2} \mathrm{H}_{5}$ in hexanes. Locate the product by UV visualization. A razor blade should be used to scrape the silica containing the product off the plate. Collect the silica in a fritted funnel and flush it with EtOAc. The pure product can be isolated from the filtrate.

$\triangle$ CRITICAL STEP In some cases, the aryl iodide product also contains a small amount of aryl bromide starting material due to the separation difficulties. To solve this problem, a longer reaction time is needed.

? TROUBLESHOOTING

PAUSE POINT The raw products can be stored on the shelf in the dark at room temperature, and they remain stable for at least 2 weeks. 


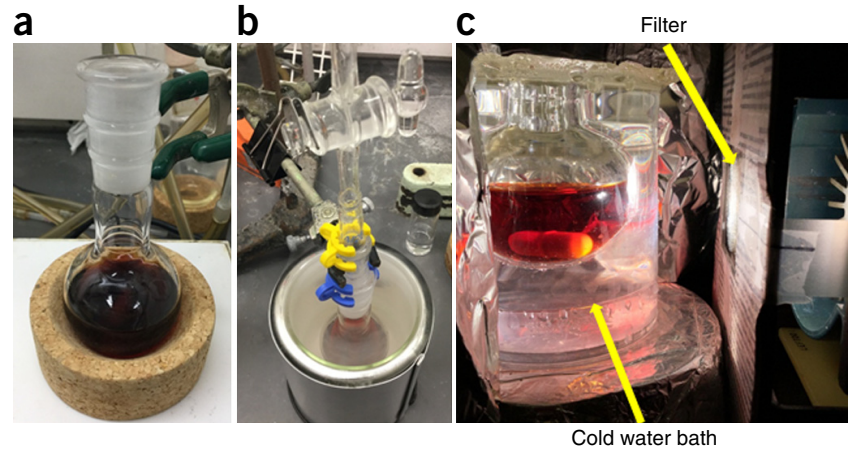

Figure 8 | Reaction setup for gram-scale procedure. (a) Quartz flask with homogeneous reactant mixture. (b) System degassing by the freeze-pump-thaw operation. (c) Photoreaction carried out in a cold-water bath under photo-irradiation from a 300W UV lamp with filter.

\section{Gram-scale reaction-reaction setup $\bigcirc$ TIMING $40 \mathrm{~min}$} 10| Weigh $1.104 \mathrm{~g}$ of 4-bromobenzonitrile $(6 \mathrm{mmol})$ and $1.80 \mathrm{~g}$ of $\mathrm{NaI}$ (2 equiv.) into a $50-\mathrm{ml}$ round-bottom quartz flask with a $20-\mathrm{mm}$ stir bar. Add $27 \mathrm{~mL}$ of $\mathrm{CH}_{3} \mathrm{CN}$ to the quartz flask and stir until it has fully dissolved. Next, add $3 \mathrm{ml}$ of $\mathrm{I}_{2}$ solution $\left(0.2 \mathrm{M}\right.$ in $\left.\mathrm{CH}_{3} \mathrm{CN}\right)$ dropwise to the quartz tube under stirring until there is no more color change (Fig. 8a).

11| Connect the quartz flask with a Schlenk line through a glass stopcock adaptor, and then perform four freezepump-thaw cycles. For each freeze-pump-thaw cycle, make sure that the stopcock is closed and freeze the reactants by using liquid nitrogen. When the solvent is frozen, open the stopcock to vacuum and pump off the atmosphere for 2-3 min (Fig. 8b). Close the stopcock and thaw the solvent slowly (10-15 min) until it is fully melted. Repeat these steps until no gas is released from the solution (four times is sufficient). Fill the flask with ultra-purified argon gas, and close the stopcock.

\section{Gram-scale reaction-iodination of 4-bromobenzonitrile (1b) under UV irradiation $\bigcirc$ TIMING $36 \mathrm{~h}$}

12| Put the airtight quartz flask with the closed stopcock into a large jacketed quartz container full of cold water. Place a 300W UV lamp with a 225-nm long-pass filter $5 \mathrm{~cm}$ away from the quartz flask. Start the stirring and turn on the UV lamp (Fig. 8c).

$\triangle$ CRITICAL STEP The jacketed quartz container, which is connected to a cooling water circulator, can keep the reaction temperature $\sim 20^{\circ} \mathrm{C}$ under strong photo-irradiation.

\section{? TROUBLESHOOTING}

13| (Optional) Use GC-MS to monitor the progress of the reaction. To do this, remove $100 \mu \mathrm{l}$ of the supernatant solution and dilute it by adding $\mathrm{CH}_{3} \mathrm{CO}_{2} \mathrm{C}_{2} \mathrm{H}_{5}(1 \mathrm{ml})$. Pass this solution through a 2-cm plug of silica gel to remove inorganic salts. Analyze the resulting clear solution by GC-MS, as described in the Equipment Setup (Fig. 9). To maintain the argon atmosphere during the extraction, take the sample out from the top end of the stopcock quickly by using a syringe with a long needle.

14| Stop the reaction when the reaction is complete (e.g., after $36 \mathrm{~h}$ ) by turning off the lamp.

\section{Gram-scale reaction-purification of the product $\bigcirc$ TIMING $3 \mathbf{h}$}

15| Transfer the resulting suspension to a $100-\mathrm{ml}$ round-bottom flask, and connect this to the rotary evaporator to remove the $\mathrm{CH}_{3} \mathrm{CN}$ solvent.

16| Add $60 \mathrm{ml}$ of $\mathrm{Na}_{2} \mathrm{~S}_{2} \mathrm{O}_{3}$ aqueous solution $(0.1 \mathrm{M})$ to reduce excess $\mathrm{I}_{2}$, and transfer all the reactants to a 120 -ml separation funnel. Wash the round-bottom flask with excess $\mathrm{CH}_{3} \mathrm{CO}_{2} \mathrm{C}_{2} \mathrm{H}_{5}(3 \times 15 \mathrm{ml})$, and transfer this to the separation funnel as well. 
17| Collect the top layer, and transfer it to an Erlenmeyer flask. Add $5.0 \mathrm{~g}$ of anhydrous $\mathrm{Na}_{2} \mathrm{SO}_{4}$. After $30 \mathrm{~min}$, use a Büchner funnel to remove the $\mathrm{Na}_{2} \mathrm{SO}_{4}$.

18| Transfer the organic solution to a round-bottom flask, and connect this to the rotary evaporator to remove the solvent.

19| Purify the residue on a SNAP flash-chromatography cartridge (10 g, Biotage SNAP Ultra) by means of an automated flash purification system with a 254-nm UV detector (or by running a standard flash chromatography column) using $5 \%$ (vol/vol) $\mathrm{CH}_{3} \mathrm{CO}_{2} \mathrm{C}_{2} \mathrm{H}_{5}$ in hexanes to provide the white solid product $\left(R_{\mathrm{f}}=0.48 ;\right.$ Fig. 10).

20| Collect the fractions that contain the pure product in a round-bottom flask, and connect this to the rotary evaporator to remove the solvent at $40^{\circ} \mathrm{C}$.

PAUSE POINT The raw products can be stored on the shelf in the dark at room temperature, and they remain stable for at least 2 weeks.

\section{$?$ TROUBLESHOOTING}

Troubleshooting advice can be found in Table 1.

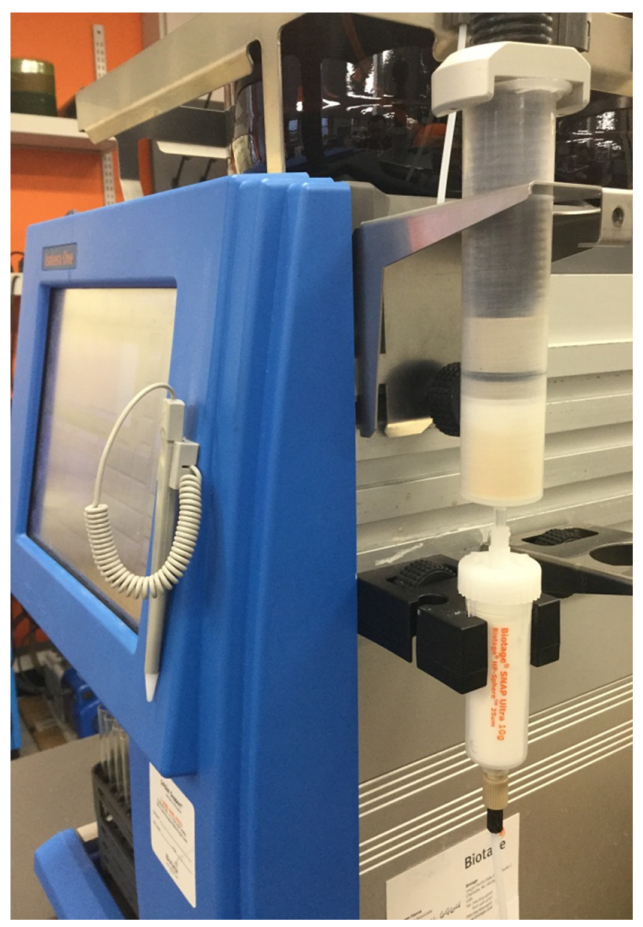

Figure 10 Separation of the reaction mixture by the automated flash purification system.

TABLE 1 | Troubleshooting table.

\begin{tabular}{|c|c|c|c|}
\hline 2 & $\begin{array}{l}\text { Solid reactant sticks to the } \\
\text { wall of the quartz tube }\end{array}$ & Thawing took place too quickly & Thaw slowly in air without using a water bath or a heater \\
\hline 4 & $\begin{array}{l}\text { Reaction mixtures turn black } \\
\text { during the photoreaction }\end{array}$ & $\begin{array}{l}\text { Leakage of oxygen from air, } \\
\text { which may oxidize the reactant }\end{array}$ & $\begin{array}{l}\text { Make sure that the freeze-pump-thaw degassing operation } \\
\text { is performed four times with ultra-purified argon }\end{array}$ \\
\hline 9 & Product turns light yellow & $\begin{array}{l}\text { Aryl iodides are sensitive to } \\
\text { light }\end{array}$ & $\begin{array}{l}\text { Avoid exposure to strong light during the whole purification } \\
\text { procedure }\end{array}$ \\
\hline 12 & $\begin{array}{l}\text { Low yield or many side } \\
\text { reactions }\end{array}$ & Temperature is too high & $\begin{array}{l}\text { Use a cold-water bath and a jacketed quartz container } \\
\text { connected to a powerful cooling system that can keep the } \\
\text { reaction temperature } \sim 20^{\circ} \mathrm{C} \text { under strong photo-irradiation }\end{array}$ \\
\hline
\end{tabular}

\section{TIMING}

Steps 1-3, small-scale reaction-reaction setup: $20 \mathrm{~min}$

Steps 4 and 5, small-scale reaction-iodination of 4-bromobenzonitrile (1b) under UV irradiation: $36 \mathrm{~h}$

Steps 6-9, small-scale reaction-purification of the product: $2 \mathrm{~h}$

Steps 10 and 11, gram-scale reaction-reaction setup: $40 \mathrm{~min}$

Steps 12-14, gram-scale reaction-iodination of 4-bromobenzonitrile (1b) under UV irradiation: $36 \mathrm{~h}$

Steps 15-20, gram-scale reaction-purification of the product: $3 \mathrm{~h}$

\section{ANTICIPATED RESULTS}

\section{4-Iodobenzonitrile $(2 \mathrm{~b})$}

By following the procedure above, aryl iodide 4-iodobenzonitrile (2b) should be obtained as a white solid in a $93 \%$ yield $(0.1 \mathrm{mmol}$ scale, $21.3 \mathrm{mg})$ or an $86 \%$ yield $(6 \mathrm{mmol}$ scale, $1.18 \mathrm{~g})$ after purification. Obviously, the conversion rate and yield 
of a photochemical reaction depend strongly on the light intensity. Therefore, the UV light intensity at $254 \mathrm{~nm}$ was measured quantitatively for either a photoreactor $\left(4 \mathrm{~mW} \mathrm{~cm}-2,0.1\right.$-mmol-scale reaction) or a $300 \mathrm{~W}$ xenon lamp (20 $\mathrm{mW} \mathrm{cm}^{-2}$, gram-scale reaction) by using an optical power meter during the reaction.

The product was confirmed by using GC-MS and NMR. ${ }^{1} \mathrm{H}$ NMR $\left(500 \mathrm{MHz}, \mathrm{CDCl}_{3}\right) \delta 7.85(\mathrm{~d}, \mathrm{~J}=8.5 \mathrm{~Hz}, 2 \mathrm{H}), 7.37$ $(\mathrm{d}, J=8.5 \mathrm{~Hz}, 2 \mathrm{H}) .{ }^{13} \mathrm{C}$ NMR $\left(126 \mathrm{MHz}, \mathrm{CDCl}_{3}\right) \delta 138.5,133.2,118.2,111.8,100.3$. Mp 122-123 ${ }^{\circ} \mathrm{C}$. IR (neat): $v=2,226$, $1,577,1,473,1,390,1,053,1,009,818,540 \mathrm{~cm}^{-1}$; MS: $\mathrm{m} / \mathrm{z}(\%) 229.0(\mathrm{M}+, 100)$.

ACKNOWLEDGMENTS This work was financially supported by the Canada Research Chair (Tier 1) foundation, the Natural Sciences and Engineering Research Council of Canada, the Fonds de recherchésur la nature et les technologies, the Canada Foundation for Innovation (CFI) and McGill University.

AUTHOR CONTRIBUTIONS L.L. and W.L. designed the study; L.L. optimized and performed the experiments and W.L. discovered the initial reaction; L.L., W.L., X.M., C.-J.L. and Z.M. wrote the manuscript; C.-J.L. and Z.M. initiated and supervised the project; all authors discussed the results and commented on the manuscript.

COMPETING FINANCIAL INTERESTS The authors declare no competing financial interests.

Reprints and permissions information is available online at http://www.nature com/reprints/index.html.

1. Bunnett, J.F. \& Zahler, R. Aromatic nucleophilic substitution reactions. Chem. Rev. 49, 273-412 (1951).

2. Bolm, C., Hildebrand, J.P., Muñiz, K. \& Hermanns, N. Catalyzed asymmetric arylation reactions. Angew. Chem. Int. Ed. 40, 3284-3308 (2001).

3. Popov, I., Lindeman, S. \& Daugulis, 0. Copper-catalyzed arylation of 1H-perfluoroalkanes. J. Am. Chem. Soc. 133, 9286-9289 (2011).

4. Bunevičius, R., Kažanavičius, G., Žalinkevičius, R. \& Prange, A.J. Effects of thyroxine as compared with thyroxine plus triiodothyronine in patients with hypothyroidism. N. Engl. J. Med. 340, 424-429 (1999).

5. Pimlott, S.L. \& Sutherland, A. Molecular tracers for the PET and SPECT imaging of disease. Chem. Soc. Rev. 40, 149-162 (2011).

6. Hallouard, F., Anton, N., Choquet, P., Constantinesco, A. \& Vandamme, T. Iodinated blood pool contrast media for preclinical X-ray imaging applications. Biomaterials 31, 6249-6268 (2010).
7. Seevers, R.H. \& Counsell, R.E. Radioiodination techniques for small organic molecules. Chem. Rev. 82, 575-590 (1982).

8. Barluenga, J., González, J.M., Martín, M.A.G., Campos, P.J. \& Asensio, G. Acid-mediated reaction of bis(pyridine)iodonium(I) tetrafluoroborate with aromatic compounds. A selective and general iodination method. J. Org. Chem. 58, 2058-2060 (1993).

9. Takagi, K., Hayama, N. \& Inokawa, S. The in situ-generated nickel(0)catalyzed reaction of aryl halides with potassium iodide and zinc powder. Bull. Chem. Soc. Jpn. 53, 3691-3695 (1980).

10. Yang, S.H., Li, C.S. \& Cheng, C.H. Halide exchange reactions between aryl halides and alkali halides catalyzed by nickel metal. J. Org. Chem. 52, 691-694 (1987).

11. Sheppard, T.D. Metal-catalysed halogen exchange reactions of aryl halides. Org. Biomol. Chem. 7, 1043-1052 (2009).

12. Klapars, A. \& Buchwald, S.L. Copper-catalyzed halogen exchange in aryl halides: an aromatic Finkelstein reaction. J. Am. Chem. Soc. 124, 14844-14845 (2002).

13. Casitas, A., Canta, M., Solà, M., Costas, M. \& Ribas, X. Nucleophilic aryl fluorination and aryl halide exchange mediated by a $\mathrm{Cu}^{\mathrm{I}} / \mathrm{Cu}^{\mathrm{III}}$ catalytic cycle. J. Am. Chem. Soc. 133, 19386-19392 (2011).

14. Cant, A.A., Bhalla, R., Pimlott, S.L. \& Sutherland, A. Nickel-catalysed aromatic Finkelstein reaction of aryl and heteroaryl bromides. Chem. Commun. 48, 3993-3995 (2012).

15. Chen, M., Ichikawa, S. \& Buchwald, S.L. Rapid and efficient coppercatalyzed Finkelstein reaction of (hetero)aromatics under continuous-flow conditions. Angew. Chem. Int. Ed. 54, 263-266 (2015).

16. Li, L. et al. Photo-induced metal-catalyst-free aromatic Finkelstein reaction. J. Am. Chem. Soc. 137, 8328-8331 (2015).

17. M'Halla, F., Pinson, J. \& Saveant, J.M. The solvent as H-atom donor in organic electrochemical reactions. Reduction of aromatic halides. J. Am. Chem. Soc. 102, 4120-4127 (1980).

18. Rasmusson, M. et al. Photodissociation of bromobenzene in solution. Chem. Phys. Lett. 367, 759-766 (2003). 